\title{
TOTAL PHENOLS AND ANTIOXIDANT ACTIVITIES OF NATURAL HONEYS AND PROPOLIS COLLECTED FROM DIFFERENT GEOGRAPHICAL REGIONS OF ETHIOPIA
}

\author{
Dubero Sime $^{1}$, Minaleshawa Atlabachew ${ }^{2,3, *}$, Mesfin Redi-Abshiro ${ }^{2}$ and Tewabech Zewde ${ }^{1}$ \\ ${ }^{1}$ Department of Physiology, School of Medicine, College of Health Sciences, Addis Ababa \\ University, P.O Box 9086, Addis Ababa, Ethiopia \\ ${ }^{2}$ Department of Chemistry, College of Natural Sciences, Addis Ababa University, P.O. Box \\ 1176, Addis Ababa, Ethiopia \\ ${ }^{3}$ Department of Chemistry, College of Science, Bahir Dar University, P.O. Box 79, Bahir Dar, \\ Ethiopia
}

(Received December 11, 2013; revised March 21, 2015)

\begin{abstract}
In this study, ten honey and five propolis samples from different geographical origins were tested. Both honey and propolis samples showed high content of total phenolic compounds (330-610 mg gallic acid equivalent (GAE)/100 g honey; 365-1022 mg GAE/g ethanol extract of propolis (EEP). The total flavonoids ranged from (15.1-42.6 mg catechin equivalent (CE)/100 g for honey; to 123-74 mg CE/g for EEP. These honeybee products of Ethiopia had high total radical scavenging properties with respect to 2,2-diphenyl-1-picrylhydrazyl (DPPH); $18.1-59.8 \%$ and $48.6-87.8 \%$ for honey and EEP respectively. Furthermore, the hydroxymethylfurfural (HMF) of the honey samples was found to be low with a mean value of $4.8 \mathrm{mg} / \mathrm{kg}$ suggesting that the samples were of good quality. The antioxidant properties of the products showed a good correlation $\left(r^{2}=0.50-0.82\right)$ with their polyphenolic contents.
\end{abstract}

KEY WORDS: Ethiopia, Honey, Propolis, Polyphenols, Flavonoids, Antioxidants

\section{INTRODUCTION}

Honey and propolis are easily accessible honeybee products which are becoming increasingly popular due to their potential role in contributing to human health [1]. Honey is a natural substance produced by honeybees (Apis mellifera) from the nectar of blossoms and secretions of plants. It is known to have both enzymatic and non-enzymatic antioxidant activities [2, 3]. Though, honey is a highly supersaturated solution of a complex mixture of sugars, it also contains small amount of other constituents including minerals, proteins, vitamins, organic acids, flavonoids, phenolic compounds, and enzymes; catalase, peroxides, glucose oxydase and other phytochemicals [3-5].

5-Hydroxymethyl-2-furaldehyde (HMF) is an aldehyde that is often used as an indicator for the honey quality. HMF and $\mathrm{pH}$ of honey are considered as important physicochemical parameters to determine the status of honey samples [6]. Because, HMF formation increases as the result of bad storage and heating, it is an excellent indicator of the honey's freshness and proper storage [7]. According to ANNEXII-Composition Criteria for Honey of the EU Council Directive 2001/110/EC, the HMF content of honey should be under $40 \mathrm{mg} / \mathrm{kg}$ in general, and under $80 \mathrm{mg} / \mathrm{kg}$ for honeys from regions of tropical climate [8].

Depending on the geographical and climatic conditions, different types of honey contain a wide range of phytochemicals including polyphenols and phenolic acids which act as antioxidants [9]. The main polyphenols in honey are the flavonoids with contents varying between 60 and $460 \mu \mathrm{g} / 100 \mathrm{~g}$ of honey [2]. Recent studies on honeys indicated that the biological actions of honey can be ascribed to its polyphenolic contents, which are elucidated by its antioxidant, anti-inflammatory, anti-proliferative and antimicrobial actions [10].

\footnotetext{
*Corresponding author. E-mail: atminale2004@yahoo.com; minaleshewaa@bdue.edu.et
} 
Propolis is a natural honeybee product with sticky and resinous nature. It is collected by honey bees (Apis mellifera) from the buds and barks of different trees and enriched in thehive by the addition of salivated secretions and wax [11]. Propolis is widely used as a popular remedy in folk medicine and it does have high potential for use in human and veterinary medicine [11]. Like honey, propolis chemical variability is due to its plant origin and different geographic locations of the source plants [12]. Kumazawa et al. [13] have reported that more than 300 compounds including different flavonoids, polyphenolic esters, terpenoids, steroids, amino acids, caffeic acids and their esters, and inorganic compounds have been identified in propolis samples. Phytochemical investigations of propolis have demonstrated the presence of flavonoids and polyphenolic components as the main active ingredients having potent antioxidant activities. The antioxidant property of propolis seems to be responsible for its anti-carcinogenesis and hepatoprotective activities $[14,15]$.

The use of analytical methods for the determination of phenolic acids and flavonoids individually or as a group at the same time, has been related to the floral and geographical origins of honey and propolis. Folin-Denis and Folin-Ciocalteu reagents were widely used for estimation of plant phenols through color changes. Folin-Denis colorimetry was considered the best and "official" method but was subject to precipitations that interfered with colorimetry, yet gives good result [16]. One of the important functions of antioxidants in the living system is preventing the disturbance and functional loss of biological membranes and enzymes by scavenging the free radicals that otherwise induce oxidation of lipids, proteins, and DNA [17]. The antioxidant activity of phenolics is mainly due to their redox properties, which allows them to act as reducing agents $[18,19]$. To analyse the antioxidant activity of honey and propolis, the analytical methods commonly used refers to the sample's reducing capacity using the FolinCiocalteu or Folin-Denis and ferric reducing antioxidant power (FRAP) tests as well as antiradical activity with the 2,2-diphenyl-1-picryl-hydrazyl (DPPH) radical scavenging assays [4].

The antioxidant properties of honey and propolis believed to be at the heart of their polyphenolic compounds. The Ethiopian natural honey and propolis are thought to be of different varieties due to the unique and highly diverse flora of the country because of its rich variety of environmental features ranging from semi-desert to mountain forests and its wide range of ecological, edaphic, and climatic conditions. There are over 7000 flowering plants species recorded, of which $12 \%$ or more are probably endemic to Ethiopia [20]. To the best of our knowledge, no study has been reported on the phenolic contents and antioxidant properties of Ethiopian honey and propolis samples to date. Therefore, this study was designed to determine the total phenolic and flavonoid contents, and evaluate the radical scavenging activities of ten honey samples and five propolis samples collected from different geographical sources of Ethiopia.

\section{EXPERIMENTAL}

\section{Equipment and reagents}

Equipment. Lyophilizer (Operon, OPR-FDU-5012, Korea), Double beam UV/VIS NIR spectrometry (Perkin Elmer, Lambda 950, Waltham, MA 02451, USA) and Rotavapor (Buchi, Switzerland) were used.

Reagents. All the chemicals and reagents used in this study were of analytical grade reagents. Anhydrous sodium carbonate, zinc acetate and sodium bisulfite (Research Lab Fine Chem Industries, Mumbai, India), orthophosphoric acid (85\%) and sodium molybdate dehydrate (98\%) (BDH, England), anhydrous $\mathrm{AlCl}_{3}$ and $\mathrm{Na}_{2} \mathrm{NO}_{2}$ (Fluka, Switzerland), sodium tungstate $\left(\mathrm{Na}_{2} \mathrm{WO}_{4} \cdot 2 \mathrm{H}_{2} \mathrm{O}\right)$ and phosphomolybdic acid (Scharlau Chememia, USA), ethanol and methanol (Alpha Chemika, India), gallic acid, chatechin, 2,2-diphenyl-1-picrylhydrazyl radical (DPPH), 
and ascorbic acid (Sigma-Aldrich, USA) were used as received. Folin-Ciocalteu was prepared in the laboratory.

\section{Preparation of Folin-Ciocalteau reagent}

Into $100 \mathrm{~mL}$ of round bottom flask, $10 \mathrm{~g}$ of sodium tungstate and $2.5 \mathrm{~g}$ of sodium molybdate were dissolved in $70 \mathrm{~mL}$ of distilled water. To the mixture $5 \mathrm{~mL}$ of $85 \%$ phosphoric acid and 10 $\mathrm{mL}$ of concentrated hydrochloric acid were added. After the solution was refluxed for 10 hours, $15 \mathrm{~g}$ of lithium sulfate, $5 \mathrm{~mL}$ of distilled water and 1 drop of bromine were sequentially added to the solution and refluxed for $15 \mathrm{~min}$. The resulted mixture was allowed to cool at room temperature and was diluted to $100 \mathrm{~mL}$ with distilled water.

\section{Honey samples}

Honey samples were collected from six different geographical areas namely Agarfa Agricultural Technical and Vocational Education Training (ATVET) college (Bale zone, Oromia region), Alage ATVET college (West Arsi Zone Oromia region), Wolaita Soddo ATVET college (Wolaita zone, Southern Nation Nationality peoples, SNNP region), Holeta (West Showa zone, Oromia region), Bore (Guji zone, Oromia region), and Addis Ababa (Akaki-Kality and Yeka Kifle-Ketema of Addis Ababa City Administrative region) from May, 2011 to November, 2012 (Table 1). All samples were stored in capped airtight plastic and glass jars at room temperature until analysis.

Table 1 . The ten honey samples, the site and dates of their collections.

\begin{tabular}{|c|c|c|c|c|}
\hline Sample code & Site of collection & Harvest date & Type of honey & Production type \\
\hline AAKal 1 (July) & Addis Ababa Kality area & July, 2012 & Multi floral & Traditional \\
\hline AAKal 2 (Sept.) & Addis Ababa Kality area & September, 2012 & Multi floral & Traditional \\
\hline AAQab (June) & Addis Ababa Qabenna area & June, 2012 & Multi floral & Modern \\
\hline Alage (July) & Alage ATVET & July, 2011 & Multi floral & Modern \\
\hline Agarfa (May) & Agarfa ATVET & May, 2011 & Multi floral & Modern \\
\hline Agarrfa (Oct.) & Agarfa ATVET & October, 2011 & Multi floral & Modern \\
\hline Bore (May) & Bore & May, 2011 & Multi floral & Modern \\
\hline Holeta (July) & Holeta Bee research center & July, 2012 & Multi floral & Modern \\
\hline Wolaita 1 (July) & Wolaita Sodo ATVET & July, 2011 & Multi floral & Modern \\
\hline Wolaita 2 (Nov.) & Wolaita Sodo ATVET & November, 2011 & Multi floral & Modern \\
\hline
\end{tabular}

ATVET = Agricultural Technical and Vocational Education Training; AAK = Addis Ababa Kality area; AAQab = Addis Ababa Qabana area; Modern = improved beehives and honey production systems employed; Traditional = traditional basket beehives and honey production used.

Table 2. The five Propolis samples, and the site and date of collections.

\begin{tabular}{|c|c|c|}
\hline Name of sample & Site of collection & Time of collection \\
\hline Alage & Alage ATVET & July, 2011 \\
\hline Agarfa & Agarfa ATVET & June, 2011 \\
\hline Holeta & Holeta Bee research & June, 2011 \\
\hline Gedo & Gedo area & June, 2011 \\
\hline Wolaita & Wolaita Sodo ATVET & July, 2011 \\
\hline
\end{tabular}

ATVET $=$ Agricultural Technical and Vocational Education Training.

\section{Collection of the propolis samples}

Five propolis samples were collected from honeybee hives in the apiary sites of Agarfa ATVET, Alage ATVET, Wolaita Sodo ATVET, Holeta and Gedo areas of West Showa zone from May 
2011 to November 2011 by trained technical experts. The propolis samples were collected from different geographical areas all from the same sites as honey samples except one sample from Gedo (Table 2).

\section{Extraction of the propolis samples}

The crude propolis samples were dried in ice, crushed into pieces and cleaned from impurities by thinning between fingers with hand so that the pure propolis is sticky and elastic. Each propolis sample was weighed and mixed with $70 \%$ ethyl alcohol in a ratio of $1 \mathrm{~g}: 5 \mathrm{~mL}(\mathrm{w} / \mathrm{v})$ and the mixture was sealed in a container with intermittent shaking twice a day for 20 days [21]. The supernatant liquid was filtered with Whatman filter paper No. 1; the alcohol evaporated with a Rota vapor under vacuum and freeze dried by lyophilizer. The ethanol extract of propolis (EEP) was kept in a clean, airtight brown bottle in a refrigerator at $-20^{\circ} \mathrm{C}$ until used for analysis.

\section{Determination of hydroxymethyl furfural (HMF) of the honey samples}

Five gram of each honey sample was dissolved in $25 \mathrm{~mL}$ of distilled water to determine the HMF of the honey samples. The solution was quantitatively transferred to $50 \mathrm{~mL}$ flask and 0.5 $\mathrm{mL}$ of Carrez Solution I (150 mg/mL potassium ferrocyanide) and $0.5 \mathrm{~mL}$ of Carrez Solution II ( $300 \mathrm{mg} / \mathrm{mL}$ zinc acetate) were added. After the mixture was vigorously shaken and mixed well, the solution was brought to a final volume of $50 \mathrm{~mL}$ with distilled water. Aliquots of $5 \mathrm{~mL}$ were put in two test tubes; to the first test tube $5 \mathrm{~mL}$ of distilled water was added (sample solution); and to the second one $5 \mathrm{~mL}$ of $0.2 \%$ sodium bisulfite solution was added (reference solution). Then the HMF content of the ten honey samples were determined according to the White method by measuring the absorbance of the solutions at 284 and $336 \mathrm{~nm}$ with a UV-VIS spectrophotometer as suggested by International Honey Commission [22]. The HMF content was calculated using the formula;

$$
H M F=\left(A_{284}-A_{336}\right) * 149.7 * 5 * \frac{D}{W}(m g / k g)
$$

Where $\mathrm{A}_{\mathbf{2 8 4}}=$ absorbance at $284 \mathrm{~nm}, \mathrm{~A}_{336}=$ absorbance at $336 \mathrm{~nm}, 149.7=\frac{126 * 1000 * 1000}{16830 * 10 * 5}=$

constant, $\mathrm{D}=$ dilution factor and $\mathrm{W}=$ weight of honey sample (g) [22].

Determination of total phenolic compounds in honey samples

The total phenolic compounds of the ten honey samples were determined according to the FolinCiocalteau method [23]. The solution of each honey sample was prepared by dissolving $2.5 \mathrm{~g}$ honey in $50 \mathrm{~mL}$ distilled water to obtain $0.05 \mathrm{mg} / \mathrm{mL}$ solution. One milliliter of properly diluted honey solution was mixed with $0.5 \mathrm{~mL}$ of Folin-Ciocalteau reagent and then $2.5 \mathrm{~mL}$ of $7.5 \%$ sodium carbonate $\left(\mathrm{Na}_{2} \mathrm{CO}_{3}\right)$ solution was added to the mixture. The mixture was kept in the dark for $90 \mathrm{~min}$ for reaction to occur. Then the absorbance of a blue colored mixture was measured at $740 \mathrm{~nm}$ using double beam UV/VIS NIR spectrometry. Gallic acid was used as a reference standard. The measurements were done in triplicate and the absorbance was read at $740 \mathrm{~nm}$ with a double beam UV/VIS NIR spectrometry. The results were expressed as mg gallic acid equivalents (GAE) per $100 \mathrm{~g}$ of honey.

\section{Determination of total phenolic compounds in ethanol extracts of propolis (EEP)}

The total phenolics in EEP were determined spectrophotometrically by the Folin-Ciocalteau method as for honey samples employing gallic acid as a standard [16]. Ten milligram of EEP was dissolved in $25 \mathrm{~mL}$ of $70 \%$ ethanol. One milliliter $(0.4 \mathrm{mg} / \mathrm{mL})$ of the solution was mixed with $0.5 \mathrm{~mL}$ of Folin-Ciocalteau reagent and $1.5 \mathrm{~mL}$ of $4 \% \mathrm{Na}_{2} \mathrm{CO}_{3}$. This formed a deep blue colored solution which was kept in dark at room temperature for $2 \mathrm{~h}$ and then the absorbance was measured at $740 \mathrm{~nm}$ with a double beam UV/VIS NIR spectrometry and results were expressed as mg gallic acid equivalent (GAE)/g ethanol extract of propolis (EEP). 


\section{Determination of total flavonoids in honey samples}

The total flavonoids content in the honey samples was determined according to calorimetric assay methods [24, 25]. The solution of each honey sample was prepared by dissolving $2.5 \mathrm{~g}$ honey in $50 \mathrm{~mL}$ distilled water. One milliliter of properly diluted honey $(0.05 \mathrm{~g} / \mathrm{mL})$ was mixed with $4 \mathrm{~mL}$ of distilled water and $0.3 \mathrm{~mL}$ of $(5 \% \mathrm{w} / \mathrm{v}) \mathrm{NaNO}_{2}$ was added. Then, $0.3 \mathrm{~mL}$ of $(10 \%$ w/v) $\mathrm{AlCl}_{3}$, and $2 \mathrm{~mL}$ of $1 \mathrm{M}$ solution of $\mathrm{NaOH}$ were added after 5 min and 6 min, respectively. The mixture was diluted to $10 \mathrm{~mL}$ by the addition of distilled water. The mixture was shaken vigorously and the absorbance of the mixture was read at $503 \mathrm{~nm}$ with a double beam UV/VIS NIR spectrometry. Catechin was used as a calibrator standard. The results were expressed as mg catechin equivalents (CE) per $100 \mathrm{~g}$ of honey.

Determination of total flavonoids in ethanol extracts of propolis (EEP)

The total flavonoid contents of different EEP were determined using the aluminium chloride colorimetric method [24, 25]. To $1 \mathrm{~mL}$ of the EEP solution, $0.3 \mathrm{~mL}$ of $(5 \% \mathrm{w} / \mathrm{v}) \mathrm{NaNO}_{2}, 0.3 \mathrm{~mL}$ of $10 \% \mathrm{AlCl}_{3}$ and $2 \mathrm{~mL}$ of $1 \mathrm{M}$ solution of $\mathrm{NaOH}$ were added sequentially as mentioned above. Catechin in $70 \%$ ethanol solution was used as standard calibrator. Flavonoid contents were expressed as catechin equivalents (CE/g of EEP).

\section{Determination of radical scavenging activities of honey and propolis extract}

The antioxidant capacity of the honey samples and EEP was measured by evaluating the free radical-scavenging effect of the samples with 2,2-diphenyl-1-picrylhydrazyl (DPPH) radical using the method reported by Ferreira et al. [26]. Ascorbic acid was used as standard for both honey and EEP. The solution of each honey sample was prepared by dissolving $1.5 \mathrm{~g}$ honey in $20 \mathrm{~mL}$ distilled water. One milliliter of properly diluted honey solutions $(0.075 \mathrm{~g} / \mathrm{mL})$ was mixed with $0.5 \mathrm{~mL}$ of DPPH in methanol $(0.342 \mathrm{mg} / \mathrm{mL})$ and then diluted with $3 \mathrm{~mL}$ methanol. The mixture was shaken vigorously and left for $1 \mathrm{~h}$ in the dark. The reduction of the DPPH radical was then determined by measuring the absorbance of the mixture at $517 \mathrm{~nm}$ with a double beam UV/VIS NIR spectrometry. A control solution was prepared containing the same amount of methanol and DPPH. The radical-scavenging activity (RSA) was calculated as a percentage of DPPH discoloration using the equation: \% RSA $=\left[\left(\mathrm{A}_{\text {control }}-\mathrm{A}_{\text {sample }}\right) / \mathrm{A}_{\text {control }}\right] \times 100$ [26]. The antioxidant activity of the honey samples was evaluated through the free radical scavenging effect against DPPH radicals, and was compared with radical-scavenging activity of ascorbic acid as a standard substance. For ethanol extract of propolis (EEP), lyophilized extract was dissolved in $70 \%$ ethanol $(0.5 \mathrm{mg} / \mathrm{mL})$ and $1 \mathrm{~mL}$ of properly diluted sample was taken and treated as above. The antioxidant role of the EEP was also tested as its free radical inhibition power against DPPH using ascorbic acid as control substance.

\section{Statistical analysis}

All analyses were carried out in triplicate and the data were expressed as means \pm standard deviations (SD). Data were analyzed using SPSS Ver. 16 and MS Excel 2007. One-way analysis of variance (ANOVA) followed by Tukey's honestly significant difference post hoc test was used to compare the phenol contents and DPPH scavenging activity of different honey types. Differences between means at the 95\% $(\mathrm{p}<0.05)$ confidence level were considered statistically significant.

\section{RESULTS AND DISCUSSIONS}

Determination of HMF of the honey samples

Hydroxymethyl furfural (HMF) is one of most important physicochemical parameters of honey [27]. The mean value of HMF of the tested honey samples ranged from $0.1 \mathrm{mg} / \mathrm{kg}$ for honey 
sample from Alage to $11.9 \mathrm{mg} / \mathrm{kg}$ for samples from the Addis Ababa Kality area. The mean value for the ten honey samples tested in this experiment was $4.8 \mathrm{mg} / \mathrm{kg}$. These values were very low in general indicating the storage conditions and harvesting processes are good and the honey samples used in this study were of good qualities. According to International Honey Commission, the limit for HMF in honey samples from tropical regions like Ethiopia is set to be $80 \mathrm{mg} / \mathrm{kg}$ while that from temperate region is $40 \mathrm{mg} / \mathrm{kg}$ [22].

\section{Ethanol extraction of the propolis samples}

As crude propolis samples contain plant resins, bees wax and insoluble material, the use of $70 \%$ ethanol for extracting the bioactive components (such as polyphenolic compounds) and to remove the bees wax of the samples is reasonable. This is because one of the factors that affects the yield and composition of hydro-ethanolic extracts of propolis is the concentration of ethanol used; solvents containing $70 \%$ of ethanol or more extracted more propolis resins by maceration [28]. Accordingly, the yield of the five propolis samples were obtained after macerating the samples for 20 days with intermittent shaking and lyophilazation after evaporating the alcohol component of the supernatant solution with a Rota vapor under vacuum. The yield ranged from 11.7\% for sample from Agarfa (Bale) to $16.7 \%$ for sample from Wolaita Soddo (Table 3).

Table 3. The ethanol extract of propolis (EEP) product yield.

\begin{tabular}{|c|c|c|c|}
\hline Sample name & Amount soaked (g) & Yield (g) & Yield (\%) \\
\hline Alage & 110 & 13.2 & 12.0 \\
\hline Agarfa & 80 & 9.4 & 11.7 \\
\hline Holeta & 90 & 12.6 & 14.0 \\
\hline Gedo & 120 & 15.4 & 12.8 \\
\hline Wolaita Soddo & 100 & 16.7 & 16.7 \\
\hline
\end{tabular}

Determination of total phenolic compounds in honey samples

The total polyphenol content of the tested honey samples ranged from 330 $\pm 38 \mathrm{mg}$ GAE/100 g (sample from Bore) to $610 \pm 5 \mathrm{mg}$ GAE/100g (sample from Woliata Soddo) area both from Southern region of Ethiopia. The two honey samples collected from Wolaita Soddo ATVET showed the highest total polyphenols (604 and $610 \mathrm{mg}$ GAE/100 g) followed by two honey samples collected from Addis Ababa Kalityarea (566 and 470 mg GAE/100 g) while the lower values were recorded for samples collected from Bore, Holeta, Addis Ababa Qabana area and Agarfa ATVET (330, 332, 337, and 377 mg GAE/100 g, respectively) (Table 4). The colors of these honey samples showed clear differences. The honey sample from Bore was white colored while Holeta and Addis Ababa Qabana area samples were light yellowish colored. The samples from Agarfa and Alage were brown in color while Wolaita Soddo and Addis Ababa Kality area samples were observed to be dark brown colored. This study confirmed that the darker honey samples have higher total phenolic contents compared to the light colored ones. Results of the present study showed that the tested Ethiopian honey samples contained the higher phenolic contents compared to the Malaysian Tualang and Gelam honeys ( $877 \pm 4 \mathrm{mg}$ GAE $/ \mathrm{kg}$ and $484 \pm 4$ $\mathrm{mg}$ GAE $/ \mathrm{kg}$, respectively) and also much higher than the Manuka honey (435 mg GAE/kg) of the New Zealand which is well investigated [4]. Even though, the Folin Ciocalteu assay method is commonly used to evaluate the total phenolic compounds in plant extracts and honey samples, it results in overestimation of the compounds due to the phosphotungstic acid and phosphomolibdic acid mixture that react with other nonphenolic reducing compounds like ascorbic acid, some sugars and amino acids that are known to interfere with the test results [4, 29, 30]. Nevertheless, the method remains useful and is largely used to evaluate the relative contents of total polyphenolic compounds in varieties of honey samples from diverse floral origins. 
Table 4. ${ }^{*}$ Total phenolic, flavonoid contents and antioxidant activity of honey samples.

\begin{tabular}{|c|c|c|c|c|}
\hline Honey type & $\begin{array}{l}\text { Total phenols (mg } \\
\mathrm{GAE}^{\mathrm{a}} / 100 \mathrm{~g} \text { honey) }\end{array}$ & $\begin{array}{l}\text { Total flavonoids (mg } \\
\mathrm{CEQ}^{\mathrm{b}} / 100 \mathrm{~g} \text { honey) }\end{array}$ & $\begin{array}{l}\% \text { DPPH inhibi- } \\
\text { tion (\% RSA) }\end{array}$ & $\begin{array}{c}\text { DPPH (mg AAE } \\
/ 100 \mathrm{~g}^{\mathrm{c}}\end{array}$ \\
\hline AAKaney) 1 (July, 2012) & $470 \pm 38$ & $42.2 \pm 2.4$ & $51.4 \pm 2.6$ & $174 \pm 9$ \\
\hline AAKal 2 (Sept., 2012) & $566 \pm 10$ & $39.2 \pm 2.0$ & $46.0 \pm 2.0$ & $155 \pm 7$ \\
\hline AAQab (June, 2012) & $377 \pm 37$ & $18.0 \pm 1.5$ & $33.1 \pm 2.3$ & $109 \pm 8$ \\
\hline Alage (July, 2011) & $419 \pm 37$ & $19.1 \pm 0.86$ & $43.4 \pm 2.9$ & $146 \pm 10$ \\
\hline Agarfa (May, 2011) & $441 \pm 36$ & $22.6 \pm 1.4$ & $49.6 \pm 3.8$ & $168 \pm 14$ \\
\hline Agarfa (Oct., 2011) & $337 \pm 30$ & $25.3 \pm 1.92$ & $22.8 \pm 2.1$ & $72.7 \pm 7.6$ \\
\hline Bore (May, 2011) & $330 \pm 38$ & $20.6 \pm 2.0$ & $18.4 \pm 1.6$ & $57.2 \pm 5.8$ \\
\hline Holeta (July, 2012) & $332 \pm 21$ & $18.4 \pm 1.0$ & $23.0 \pm 1.3$ & $73.7 \pm 4.3$ \\
\hline Wolait1(July, 2011) & $604 \pm 63$ & $34.5 \pm 3.4$ & $58.9 \pm 2.5$ & $201 \pm 9$ \\
\hline Wolaita 2 (Nov., 2011) & $610 \pm 5$ & $31.0 \pm 0.75$ & $43.9 \pm 3.8$ & $147 \pm 14$ \\
\hline Mean value & $449 \pm 28$ & $27.1 \pm 1.7$ & $39.1 \pm 2.5$ & $130 \pm 9$ \\
\hline
\end{tabular}

${ }^{\mathrm{a}}$ Gallic acid equivalent; ${ }^{\mathrm{b}}$ Catechin equivalent; ${ }^{\mathrm{c}}$ Ascorbic acid equivalent; \% RSA = percent radical scavenging activities; ${ }^{*}$ (Mean $\pm \mathrm{SD}, \mathrm{n}=3$ ).

\section{Determination of total phenolic compounds in ethanol extracts of propolis (EEP)}

The total phenolic contents of the ethanol extracts of propolis (EEP) in this study ranged from $365 \pm 37 \mathrm{mg}$ GAE/g EEP (for sample from Woliata Soddo) to $1022 \pm 60 \mathrm{mg}$ GAE/g EEP (for Alage propolis extract). The mean value for the total phenolic contents for the five propolis samples tested in this experiment was $617 \mathrm{mg} \mathrm{GAE} / \mathrm{g}$ EEP (Table 5). According to this study the Ethiopian propolis showed the highest phenolic contents compared to Indian propolis extracts (48.6 mg GAE/g EEP) [31] and Portuguese propolis (329 mg GAE/g EEP) [32]. The total phenolic content in the ethanol extracts of Ethiopian propolis samples were different according to the floral origin of the region. This holds true for propolis samples obtained from different regions in Brazil depending on the location of the hives and local floral sources [33].

Table 5. "Total phenolic, flavonoid contents and antioxidant activity of ethanol extracts of propolis (EEP).

\begin{tabular}{|c|c|c|c|c|}
\hline $\begin{array}{c}\text { Type of } \\
\text { propolis }\end{array}$ & $\begin{array}{c}\text { Total phenols } \\
\left(\mathrm{mg} \mathrm{GAE}^{\mathrm{a}} / \mathrm{g} \text { EEP) }\right.\end{array}$ & $\begin{array}{c}\text { Total flavonoids } \\
\text { (mg CEQ } / \mathrm{g} \text { EEP) }\end{array}$ & $\begin{array}{c}\text { \% DPPH inhibi- } \\
\text { tion (\% RSA) }\end{array}$ & $\begin{array}{c}\text { DPPH (mg } \\
\text { AAEc/g EEP) }\end{array}$ \\
\hline Alage & $1022 \pm 60$ & $574 \pm 101$ & $87.8 \pm 0.1$ & $455 \pm 1$ \\
\hline Agarfa & $666 \pm 28$ & $139 \pm 1$ & $49.9 \pm 1.8$ & $253 \pm 10$ \\
\hline Gedo & $597 \pm 21$ & $170 \pm 5$ & $86.4 \pm 0.2$ & $448 \pm 1$ \\
\hline Holeta & $433 \pm 32$ & $123 \pm 4$ & $71.7 \pm 1.9$ & $369 \pm 10$ \\
\hline Wolaita & $365 \pm 37$ & $218 \pm 4$ & $48.6 \pm 0.9$ & $247 \pm 5$ \\
\hline Mean value & $617 \pm 36$ & $224 \pm 5$ & $68.9 \pm 0.9$ & $354 \pm 5$ \\
\hline
\end{tabular}

${ }^{\mathrm{a}}$ Gallic acid equivalent; ${ }^{\mathrm{b}}$ Catechin equivalent; ${ }^{\mathrm{c}}$ Ascorbic acid equivalent; \% RSA $=$ percent radical scavenging activities; ${ }^{*}$ (Mean $\pm \mathrm{SD}, \mathrm{n}=3$ ).

\section{Determination of total flavonoids inhoney samples}

Total flavonoid contents of the honey samples were lower than phenolic content and ranged from 18.0 $\pm 1.5 \mathrm{mg}$ CEQ/100 g for honey sample from Addis Ababa Qabana area to $42.2 \pm 2.4$ mg CE/100 g for honey sample from Addis Ababa Kality area. This is attributable to the differences in the type of honey samples, floral origin and season of collection to a large extent (Table 4). The two honey samples from Addis Ababa Kality area showed the highest flavonoid content followed by samples from Wolaita Soddo ATVET College. These honey samples were darker in colour but collected during different seasons (from May, 2011 to November, 2012) and also differed in their storage time (from 18 month to 2 month). The yellowish light coloured honey samples from Addis Ababa Qabana area, Holeta, Bore, Alage and Agarfa ATVET 
colleges were found to have lower flavonoid content ranging from 18.0 to $25.3 \mathrm{mg}$ CE/100 g honey. The flavonoid contents of the honey samples in this study are generally higher than that of Malaysian Tualang and Gelam honeys (234 mg CE/kg and 34.3 $\pm 1.2 \mathrm{mg}$ CE/kg, respectively) and also higher than of the Manuka honey (85.1 mg CE/kg) of the New Zealand [4].

\section{Determination of total flavonoids inPropolis extracts (EEP)}

The total flavonoid contents for the propolis samples showed the highest value $(574 \pm 10 \mathrm{mg}$ CE/g EEP) for the sample from Alage ATVET college located in the Southern region of Ethiopia while the sample from the central high land area of Holeta found to be the lowest (123 $\pm 4 \mathrm{mg} \mathrm{CE} / \mathrm{g} \mathrm{EEP}$ ) of all the five propolis extract analyzed in this study (Table 5). The mean value for the flavonoid contents of all the five propolis extracts was $224 \mathrm{mg}$ CE/g EEP. Paviani et al. [34] had reported similar results (311 mg CE/g EEP) for Brazilian green propolis. It has to be noted that the propolis extract from Alage ATVET College showed the highest total phenolics (1022 mg GAE/g EEP) and flavonoids (574 mg CE/g EEP) than any other sample. However, the Wolaita Soddo ATVET propolis extract has shown the median value of flavonoid content though it was found to have the lowest total phenolic content.

In this study, Ethiopian propolis samples generally showed the highest total phenolic and total flavonoid contents compared to samples from Japanese [13] and propolis samples from Greek and Cyprus which ranged from 80.2 to $338 \mathrm{mg}$ GAE/g EEP [35].

\section{Determination of radical scavenging activities of honey and propolis extract}

In human health, the radical scavenging antioxidants play their roles by scavenging reactive free radicals to protect biologically essential molecules from oxidative modification; though their effects on chronic diseases found to be contradictory and confusing; partly due to the complex effects of oxidative stress on pathogenesis [36]. The radical scavenging activities of the honey samples and propolis extracts were compared to ascorbic acid which was used as a standard antioxidant agent. The antioxidant activity of honey samples and propolis extracts were shown by their radical scavenging ability expressed as percentage of inhibition against DPPH radical.

The percent inhibition or percent radical scavenging power (\% RSA) of the honey samples ranged from $18.4 \%$ to $58.9 \%$ for samples from Bore and Wolaita, respectively. If evaluated in terms of ascorbic acid antioxidant activity the equivalent values ranged from $57.2 \mathrm{mg} \mathrm{AAE} / 100$ g honey for Bore sample to $201 \mathrm{mg}$ AAE/100 g honey for Wolaita sample (Table 4). On average the \% RSA of all honey samples tested in this experiment is $39.1 \%$ and is equivalent to $130 \mathrm{mg}$ ascorbic acid per $100 \mathrm{~g}$ honey sample analyzed. Piljac-Zegarac et al. [37] reported that the mean scavenging potential of heterofloral Croatian honey was found to be $16.7 \mathrm{mg} \mathrm{AAE} / 100 \mathrm{~g}$. The DPPH radical scavenging capacities of Ethiopian honey samples were found to be very high compared to those Croatian honeys. Two Tualang honey types with the total polyphenols content (877 mg GAE/kg and $652 \mathrm{mg} \mathrm{GAE} / \mathrm{kg}$ ) showed the best radical scavenging properties with respect to DPPH ( $81.6 \%$ and $77.3 \%$ ) of the analyzed Malaysian honey samples [4].

The percentage inhibition (\% RSA) of the EEP ranged from $48.6 \%$ to $87.8 \%$ or $247 \mathrm{mg}$ AAE/g EEP to $455 \mathrm{mg}$ AAE/g EEP. On average the \% RSA of EEP is $68.9 \%$ which corresponds to $354 \mathrm{mg} \mathrm{AAE} / \mathrm{g}$ EEP indicating that the propolis extracts showed good in vitro antioxidant properties (Table 5).

Correlations between antioxidant activity, total phenols and flavonoids content in the samples

Correlation between total phenolic and flavonoid contents and radical scavenging activity of honey and propolis extracts were analyzed. Results are depicted in Tables 6 and 7 with correlation coefficient $\left(\mathrm{r}^{2}\right)$ of $0.50-0.82$. The total flavonoid contents correlates with the total phenolic contents with correlation coefficient $\left(r^{2}\right)$ of 0.82 (Tables 6 and 7; $p<0.05$ ). In general, extracts with a high radical scavenging activity showed a high phenolic and flavonoids content as well, but good correlations could not be found among them (Tables 6 and 7). The capacity of 
free radical scavenging does not always correlate well with the capacity to inhibit oxidation. A direct correlation between radical scavenging activity and phenolic and flavonoids content of the samples failed to demonstrate by linear regression analysis. This lack of relationship is in agreement with other literatures [10,38]. It is known that only phenolic compounds with a certain structure and particularly hydroxyl position in the molecule can act as proton donating and show radical scavenging activity [39].

Table 6. Correlation between polyphenolic contents and their radical scavenging effect of whole honey samples.

\begin{tabular}{|l|c|c|c|}
\hline & Total phenols & Total flavonoids & DPPH \\
\hline Total phenols & 1 & 0.71 & 0.82 \\
\hline Total flavonoids & 0.71 & 1 & 0.63 \\
\hline DPPH & 0.82 & 0.63 & 1 \\
\hline
\end{tabular}

Table 7. Correlation between polyphenolic contents and their radical scavenging effect of propolis extracts.

\begin{tabular}{|l|c|c|c|}
\hline & Total phenols & Total flavonoids & DPPH \\
\hline Total phenols & 1 & 0.82 & 0.56 \\
\hline Total flavonoids & 0.82 & 1 & 0.50 \\
\hline DPPH & 0.56 & 0.50 & 1 \\
\hline
\end{tabular}

\section{CONCLUSIONS}

This study has reported the results of Ethiopian honey and propolis samples on their phenolic and flavonoid contents and their radical scavenging activities. The total phenolic contents of the tested Ethiopian honey and propolis samples were found to be high (average $449 \mathrm{mg}$ GAE/100 g for honey and $617 \mathrm{mg} \mathrm{GAE} / \mathrm{g}$ for EEP) compared to similar studies done elsewhere. The total flavonoid composition was $27.1 \mathrm{mg}$ CE/100 g for honey on average while that of propolis samples was $224 \mathrm{mg}$ CE /g for EEP. Honey sample from Wolaita Soddo showed the highest total phenolic content (610 mg GAE/100 g) while the highest total flavonoid value (42.2 mg CE/100 g) was recorded for the sample from Addis Ababa Kality area. The Alage propolis sample showed the highest total phenolic and flavonoid content (1022 mg GAE/g EEP and 574 $\mathrm{mg} \mathrm{CE} / \mathrm{g}$, respectively) compared to all other propolis samples.

The antioxidant activities of both honey and propolis sample expressed in terms of their radical scavenging power with respect to DPPH varied depending on their origin. The higher radical scavenging power was observed for the Wolaita Soddo sample (58.9\%) while for propolis the Alage samples showed the best antiradical activity (87.8\%). It can be noted that the antioxidant activities of both honey and propolis samples collected from different geographical origin in Ethiopia appeared to depend on their total phenolic composition. Thus, these honeybee products can be considered as easily accessible and valuable natural sources of antioxidants and dietary supplement.

\section{ACKNOWLEDGEMENTS}

The authors express their gratitude to the Department of Chemistry, Addis Ababa University, Ethiopia, for providing the laboratory facilities. Dubero Sime is thankful to Hawassa University, Ethiopia, for sponsoring his study. The authors would also like to thank ATVET colleges of Agarfa, Alage and Wolaita Soddo for providing us the honey and propolis samples.

\section{REFERENCES}

1. Gomez-Caravaca, A.M.; Gomez-Romero, M.; Arraez-Roman, D.; Segura-Carretero, A.; Fernandez-Gutierrez, A. J. Pharm. Biomed. Anal. 2006, 41, 1220.

2. Bogdanov, S.; Jurendic T.; Sieber, R.; Gallmann, P. Am. J. Collec. Nutr. 2008, 27, 677. 
3. Khalil, M.I.; Sulaiman, S.A.; Boukraa, L. Open Nutraceut. J. 2010, 3, 6.

4. Khalil, M.I.; Mahaneem, M.; Jamalullail, S.M.S.; Alam, N.; Sulaiman, S.A. J. ApiProd. ApiMed. Sci. 2011, 3, 4.

5. Erejuwa, O.O.; Sulaiman, S.A., Ab Wahab, M.S. Molecules 2012, 17, 4400.

6. Dimins, F.; Kuka, P.; Kuka, M.; Cakste, I. LLU. Raksti 2006, 16, 73.

7. Morales, V.; Sanz, M.L.; Martın-Alvareza, P.J.; Corzo, N. J. Sci. Food Agric. 2009, 89, 1332.

8. Keppy, N.K.; Allen M. An Application Note 51864, Thermo Fisher Scientific: Madison, WI, USA; 2009.

9. Jaganathan, S.K.; Mandal, M. J. Biomed. Biotech. 2009, 2009, 1.

10. Alvarez-Suarez, J.M.; Giampieri, F.; Battino, M. Curr. Med. Chem. 2013, 20, 621.

11. Bankova, V.S.; De Castro, S.L.; Marcucci, M.C. Apidologie 2000, 31, 3.

12. Bankova, V.S. J. ApiPro. ApiMed. Sc. 2009, 1, 23.

13. Kumazawa, S.; Goto, H.; Hamasaka, T.; Fukumoto, S.; Fujimoto, T.; Nakayama, T. Biosci. Biotechnol. Biochem. 2004, 68, 260.

14. Banskota, A.H.; Tezuka, Y.; Kadota, S. Phytother. Res. 2001, 15, 561.

15. Padmavathi, R.; Senthilnathan, P.; Chodon, D.; Sakthisekaran, D. Life Sci. 2006, 78, 2820.

16. Singleton, V.L.; Rossi, J.A. Amer. J. Enol. Viticult. 1965, 16, 144.

17. Niki, E. J. Berry Res. 2011, 1, 169.

18. Mihai, C.M.; Marghitas, L.A.; Dezmirean, D.S.; Barnutiu, L. Animal Sci. Biotech. 2011, 44, 100.

19. Lianda, R.L.P.; Sant’Ana, L.D.; Echevarria, A.; Castro, R.N. J. Braz. Chem. Soc. 2012, 23, 618.

20. Thomas, I.; Bekele M. Role of Planted Forests and Trees Outside Forests in Sustainable Forest Management in the Republic of Ethiopia, Planted Forests and Trees Working Papers, Working Paper 29, FAO: Rome; 2003; p 51.

21. Krell, R. FAO, Bulletin No.124, 1996,163.

22. Bogdanov, S.; Harmonized Methods of the International Honey Commission, International Honey Commission (2009). Available at www.ihc-platform.net/ihcmethods2009.pdf; Accessed, December 14, 2012.

23. Singleton,V. L.; Orthfer, R.; Lamuela-Raventos, R. M. Meth. Enzy. 1999, 299, 152.

24. Zhishen, J.; Mengcheng, T.; Jianming, W. Food Chem. 1999, 64, 555.

25. Koksal, E.; Gulcin, I. Turk. J. Agric. For. 2008, 32, 65.

26. Ferreira, I.C.F.R.; Aires, E.; Barreira, J.C.M.; Estevinho, L.M. Food Chem. 2009, 114, 1438.

27. Ajlouni, S.; Sujirapinyokul, P. Food Chem. 2010, 119, 1000.

28. Sawaya, A.C.H.F.; Cunha, I.B.S.; Marcucci, M.C. Chem. Cen. J. 2011, 5, 1.

29. George, S.; Brat, P.; Alter, P.; Amiot, M.J. J. Agric. Food Chem. 2005, 53, 1370.

30. Barros, L.; Falcao, S.; Baptista, P.; Freire, C.; Vilas-Boas, M.; Ferreira, I.C.F.R. Food Chem. 2008, 111, 61.

31. Ambardekar, R.; Gilda, S.; Mahadik, K.; Harsulkar, A.; Paradkar, A. Pharm. 2009, 3, 991.

32. Moreira, L.; Dias, L.G.; Pereira, J.A.; Estevinho, L. Food Chem. Toxicol. 2008, 46, 3482.

33. Righi, A.A.; Negri, G.; Salatino, A. Evid. Based Complement. Alternat. Med. 2013, 2013, 1.

34. Paviani, L.C.; Fiorito, G.; Sacoda, P.; Cabral, F.A. Different Solvents for Extraction of Brazilian Green Propolis: Composition and Extraction Yield of Phenolic Compounds; III Iberoamerican Conference on Supercritical Fluid: Cartagena de Indias: Colombia; April 15, 2013, 1 ; p 7

35. Kalogeropoulos, N.; Konteles, S.J.; Troullidou, E.; Mourtzinos, I.; Karathanos, V.T. Food Chem. 2009, 116, 452.

36. Niki, E. FEBS Lett. 2012, 586, 3767.

37. Piljac-Zegarac, J.; Stipcevic, T.; Belccak, A. J. ApiProd. ApiMed. Sc. 2009, 1, 43.

38. Teixeira, E.W.; Message, D.; Negri, G.; Salatino, A.; Stringheta, P.C. Evid. Based Complement. Alternat. Med. 2008, 7, 307.

39. Rice-Evans, C.A., Miller, N.J.; Paganga, G. Free Rad. Biol. Med. 1996, 20, 933. 